
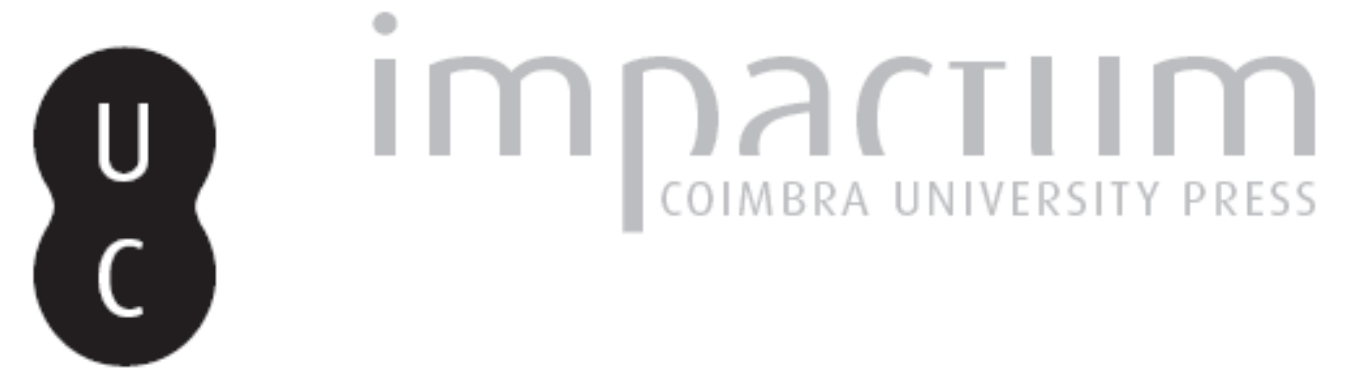

\title{
[Recensão a] Hispania Epigraphica
}

\author{
Autor(es): D'Encarnação, José
}

Publicado por: Imprensa da Universidade de Coimbra

URL persistente:

URI:http://hdl.handle.net/10316.2/45538

DOI:

DOI:https://dx.doi.org/10.14195/1647-8657_30_16

Accessed : $\quad$ 26-Apr-2023 10:56:53

A navegação consulta e descarregamento dos títulos inseridos nas Bibliotecas Digitais UC Digitalis, UC Pombalina e UC Impactum, pressupõem a aceitação plena e sem reservas dos Termos e Condições de Uso destas Bibliotecas Digitais, disponíveis em https://digitalis.uc.pt/pt-pt/termos.

Conforme exposto nos referidos Termos e Condições de Uso, o descarregamento de títulos de acesso restrito requer uma licença válida de autorização devendo o utilizador aceder ao(s) documento(s) a partir de um endereço de IP da instituição detentora da supramencionada licença.

Ao utilizador é apenas permitido o descarregamento para uso pessoal, pelo que o emprego do(s) título(s) descarregado(s) para outro fim, designadamente comercial, carece de autorização do respetivo autor ou editor da obra.

Na medida em que todas as obras da UC Digitalis se encontram protegidas pelo Código do Direito de Autor e Direitos Conexos e demais legislação aplicável, toda a cópia, parcial ou total, deste documento, nos casos em que é legalmente admitida, deverá conter ou fazer-se acompanhar por este aviso.

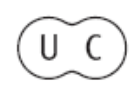


FACULDADE DE LETRAS

INSTITUTO DE ARQUEOLOGIA

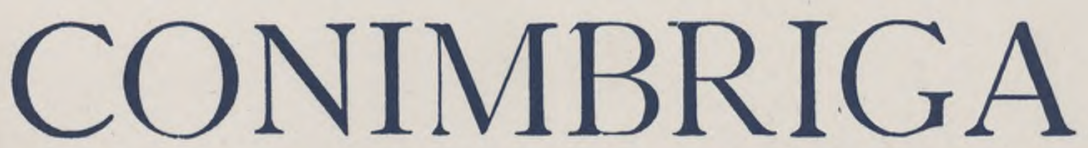

VOLUME XXX

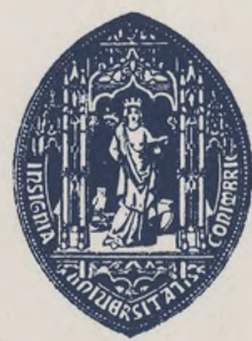

UNIVERSIDADE DE COIMBRA 
grega e nível cultural. A sua comunicação prima pela clareza e por cuidada sistematização: após definir os objectivos, trata da Gália e do helenismo, e da tipologia dos helenismos, para caracterizar, no final, a sua importância na epigrafia latina da Gália. Apesar das naturais limitações das fontes disponíveis, o grego foi aqui, concluiu Biville, «simultaneamente uma língua de cultura, uma língua internacional de trocas comerciais no Mediterrâneo, uma língua religiosa e uma língua de uso quotidiano, pelo menos em determinados círculos ou comunidades» (p. 114).

Dados sobre a poesia e a retórica são ainda limitados e acentuadamente medíocres, atesta Guy Achard (pp. 117-132), que afirma serem os epitáfios 'literários' o retrato da cultura não dos cidadãos de velha data mas sim do universo cultural dos imigrantes ou dos seus descendentes (p. 129).

Por fim - e a anteceder as conclusões do editor - Jean Guy on lança ainda um olhar sobre as informações a retirar das cerca de 150 inscrições cristãs da região em apreço, que apresentam soluções de compromisso entre o classicismo formal romano e a nova ideologia cristã emergente (pp. 135-166). De registar a boa qualidade das ilustrações.

Um volume, como se vê, do maior interesse pela variedade da temática e pela profundidade com que todos os intervenientes a souberam tratar. Exemplar, como estudo completo e global duma realidade epigráfica regional - a servir doravante de modelo e de termo de comparação.

José D ' ENCARnaÇão

Hispania EPIGRAPhica: 1，1989; 2, 1990. Madrid. Edição do Instituto de Conservación y Restauración de Bienes Culturales (Ministério da Cultura). ISBN: 84-7483-788-X.

Sob a direcção de Júlio Mangas, assessorado por um amplo conselho de redacção maioritariamente constituído por docentes do Departamento de Historia Antigua da Universidade Complutense (que coedita já o 2. ${ }^{\circ}$ volume), esta publicação vem preencher a lacuna deixada em aberto com o desaparecimento d e Hispania Antiqua Epigraphica (HAE).

Põe, além disso, ao dispor dos epigrafistas e dos historiadores da Antiguidade Clássica as múltiplas informações já recolhidas pela equipa luso-espanhola que se encarregou de lançar as bases para a reedição de um novo II volume do Corpus Inscriptionum Latinarum.

Para além das revistas de Arqueologia e de História Antiga que veiculam habitualmente informação acerca dos novos achados epigráficos, passamos assim a dispor, para a Península Ibérica, de três revistas especializadas: L'AnnéeÉpigraphique (=AE), o Ficheiro Epigráfico $(=\mathrm{FE})$ e, agora, Hispania Epigraphica (=HEp). 
Espartilhados, até há pouco, pela barreira dos mil números, que não podia ser ultrapassada em cada edição, os responsáveis pelo $\mathrm{AE}$ viam-se constrangidos a rigorosa selecção de textos, tanto mais que a revista pretende abarcar a epigrafia de todas as províncias do Império romano. Baseavam-se, por outro lado, unicamente na informação que lhes chegava às mãos, o que, por não disporem na Península Ibérica de uma rede de correspondentes abalizados, determinava insuficiências; e a circunstância de apenas terem acesso a eventuais fotografias dos monumentos levava-os amiúde a tecer considerações inoportunas acerca da correcção de leituras.

O FE - criado em 1982 e com quase duzentas inscrições inéditas publicadas até 1991 - destina-se a dar a conhecer exclusivamente textos inéditos.

A utilidade da HEp fica, assim, cabalmente justificada, pois pode vir a constituir, dado o grande leque de colaboradores, exaustiva recolha de quanto se tem escrito, nos últimos anos, acerca da epigrafia peninsular. Na verdade, se o primeiro volume inclui — como se diz na introdução — as inscrições relativas a Espanha e a Portugal publicadas entre os anos de 1984 e 1986 (salvo o que se editou em AE 1984 e 1985), o segundo (entregue na tipografia em Junho de 1990) abarca já um leque cronológico bastante maior. Não é indicado esse leque na introdução (aliás, muito sucinta), mas a simples consulta da bibliografia (mais de 320 títulos, pp. 353-372) e da tábua de correspondências (pp. 344-349) dará facilmente uma ideia dele e, inclusive, do inegável interesse que a publicação detém para os epigrafistas que se debruçam sobre os períodos romano e visigótico peninsulares. Bastará, aliás, referir que são tratadas, no I volume, 656 inscrições procedentes de território espanhol e 57 de Portugal e, no II, 742 e 167, respectivamente, para nos darmos conta da grande quantidade de informação aqui reunida.

Parece-me, todavia, que conviria esclarecer melhor quais as obras ou artigos citados na bibliografia que são considerados para efeitos deste corpus. Ou, dizendo doutra maneira, donde são retiradas, de facto, as inscrições? Por exemplo: o livro Inscrições Romanas do Conventus Pacensis (Coimbra, 1984) vem referido na bibliografia do volume 1; mas, a darmos crédito às tábuas de correspondência, nenhuma inscrição dele foi retirada. Porquê? E as inscrições inéditas (v. g., IRCP 216) que $\mathrm{AE} 1984$ não consignou? $\mathrm{FE} 55$ (= AE 1985 517) foi incluído; $\mathrm{FE} 59$ (= AE 1985 514), não. A que critérios obedece, afinal, a selecção?

Outro aspecto que, neste domínio da bibliografia, interessaria esclarecer respeita às tábuas de correspondência. Que correspondências se farão? Serão, por exemplo, sistematicamente referenciados os textos apresentados no $\mathrm{AE}$ mesmo quando for outra a fonte de informação de HEp?

Dá-se de cada texto: o local de achamento e paradeiro; brevíssima descrição; fonte bibliográfica donde é retirada a informação; leitura interpretada; pequeno comentário (quando julgado oportuno); e, sempre que possível, a datação proposta. O referido comentário dos editores vem claramente inserido entre parêntesis rectos, a fim de que se distinga bem da opinião do autor transcrito. Quanto ao modo de apresentação da leitura, seguem-se, no II volume, os critérios adoptados para as reedições do CIL, mediante a utilização de minúsculas (no I, optara-se pelo uso de maiúsculas, que continua a afigurar-se-me mais adequado e mais 'legível'), mas num 
texto corrido em que a divisão de linhas, numeradas de 3 em 3, é assinalada por uma barra (o que me parece bem e permite notável economia de espaço sem prejudicar a legibilidade).

Optou-se pela distribuição geográfica dos achados, seguindo a ordem alfabética: para a parte espanhola, as actuais províncias e, dentro delas, os municípios e seus lugares; para o território português, a arrumação faz-se por distritos, concelhos e freguesias.

Importantes são igualmente os índices, elaborados segundo o que já vem sendo hábito em obras epigráficas. No âmbito dos cognomes, não se omitiu o gentilicio sempre que ele estava presente na identificação e, no caso dos nomes únicos, também o respectivo patronímico. E se concordo com a ausência duma rubrica de «grammatica quaedam», pelas evidentes dificuldades que apresenta em volumes deste género, gostaria, porém, que «notabilia varia» estivesse presente. No I volume, inclui-se (p. 262) uma «varia» demasiado exígua: aí teria inteiro cabimento a referência a vocábulos como defunctus (inscrições 328,465 e 610, por exemplo) e cubiculum (n. ${ }^{\circ}$ 607) ou a expressões como te rogo praeteriens dic... (n. $\left.{ }^{\circ} 559\right)$ ou utere felix (n. $\left.{ }^{\circ} 607\right)$.

Torna-se difícil, bem no sei, exigir a cada um dos membros da comissão redactorial que novamente se debrucem sobre todos os textos da sua responsabilidade 'territorial'. E neste âmbito haverá, como é normal, sempre pormenores a assinalar. De resto, é por dispor de muitos textos reunidos num só volume que a perspicácia do epigrafista amiúde se acentua e desperta para novas hipóteses de leitura e de interpretação. Vejamos um que outro caso, meramente a título exemplificativo.

Afirma-se em I 327, que Masidie [sic] se documenta «pela primeira vez». O mais correcto será, decerto, afirmar que o gentilicio Masidius se documenta agora pela primeira vez na epigrafia peninsular, porque, na verdade, este nomen já é conhecido doutras paragens (cf., v. g., W. Schulze, Zur Geschichte Lateinischer Eigennamen, Berlim, 1966, pp. 189 e 427). Esse texto apresenta, por outro lado, um caso que merece alguma reflexão: a grafia MEMEMORI/AE deverá interpretar-se de preferência como testemunho duma repetição involuntária da sílaba inicial; assim, afigura-se-me mais lógico considerar que Sotera dedicou a ara Masidie Cresccntine memoriae, ou seja, "à memória de Masídia Cresccntina"; desdobrar ME em ME(ae) parece-me bastante forçado; aliás, a referência a este caso expressa no índice (p. 262) também não está correctamente transcrita.

$\mathrm{Na}$ inscrição 690 do I volume, amma deverá considerar-se um vocábulo hipocorístico ligado ao atributo caressime [sic] que se lhe segue e não um cognome: serão o aposto, «ama caríssima», de Marcela, a defunta aqui homenageada por aquele que ela criou e que modestamente se oculta, segundo tudo leva a crer, sob as siglas dos seus tria nomina (S. A. C). Desta àmia, que é autêntica e que foi achada em Vila Nova (Paialvo, Tomar), já se conhece, aliás, o paradeiro.

Comenta-se, a propósito do n. ${ }^{\circ} 770$ do II volume, que estamos perante uma revisão de leitura, mas não se explicita por quem e em que pormenores tal revisão terá sido feita. Trata-se da conhecida inscrição que memora a doação, no ano 16 a. C., de um relógio (orarium) aos Igeditanos (ILER 2082). Sucede, porém, que a fonte donde o texto é agora recolhido - a comunicação feita por Vasco Mantas ao I Congresso

\section{Conimbriga, 30 (1991), 163-197}


Peninsular de História Antiga e que vem publicada no II volume das respectivas Actas (Santiago de Compostela, 1988, p. 421) — não apresenta quaisquer desdobramentos para as siglas e abreviaturas patentes no texto. Por conseguinte, teremos de entender que as 'revisões' serão da lavra do editor de HEp. E sobre isso há algumas observações a fazer.

Em primeiro lugar, cabe, se não erro, a Giovanni Forni a primazia de ter interpretado AVGV por AVGV(sta Emerita) (cf. La tribu Papiria de Augusta Emérita, «Augusta Emerita», Madrid, 1976, pp. 33-42), quando até aí se leraAugurinus.

Quanto às siglas L. A. F. da linha 3, o seu desdobramento em L(ibens) A(nimo) $\mathrm{F}$ (ecit), que já Scarlat Lambrino propusera e sobre o qual Vasco Mantas nada acrescenta, ajusta-se melhor a uma epígrafe votiva que a uma placa monumental. Creio que uma expressão do género de L (ocus) A (dsignatus) F fuit) se enquadrará aqui mais eficazmente, na medida em que dá conta duma das funções dos magistrados, a de deliberarem sobre qual o local em que o relógio deveria ser colocado, e virá, de resto, na linha do que o próprio Vasco Mantas refere, mais adiante, isto é, a inscrição CIL II1685, que também fala de um horologium a ser posto accepto loco a republica, "em local aceite pela república".

No texto, três outros pequenos pormenores de leitura poderiam ter sido assinalados: na linha 7, a inscrição traz AMMINI (com dois MM e não apenas com um), que corresponderá ao nominativo Amminus ( e não Aminius como vem no índice, p. 277); e o patronímico é ATI(í) - por Attii —, estando o I longo em vez dos dois I como noutros casos ocorre. Uma observação melhor da fotografia teria permitido corrigir a leitura do nomen do doador: TALLIVS (em vez do tão raro IALLIVS lido até agora) - a pedra está aí um pouco danificada, mas nota-se bem a barra do $\mathrm{T}$ e só assim se compreende porque foi deixado (relativamente) tanto espaço entre a haste vertical do $\mathrm{T}$ e $\mathrm{o}$ arranque do $\mathrm{A}$.

E, já agora, para nos mantermos na Egitânia, no n. ${ }^{\circ} 771$ deverá ler-se Igaedit(anorum) lib(ertus), em vez de Igaedit(ani).

$A$ dedicatória aos Lares Aquites (n. ${ }^{\circ} 779$ do II volume) já era conhecida (cf. Fouilles de Conimbriga, II, n. ${ }^{\circ}$ ), como José Manuel Garcia oportunamente sublinhou. Só que a àmia se perdera e apenas a primeira linha fora referida pelo seu primeiro achador. Tal circunstância deveria, em meu entender, ter sido assinalada, assim como se deverá corrigir a respectiva translineação: a identificação da divindade ocupa apenas a primeira linha.

Louve-se, pois, o elevado interesse da iniciativa a que ousadamente a equipa chefiada pelo Doutor Júlio Mangas decidiu lançar ombros. Imprescindível será, porém, a colaboração de todos os epigrafistas e investigadores da História Antiga peninsular, para que o êxito seja cada vez mais duradouro.

JoSÉ D’ENCARNAÇÃo 